\title{
OPEN DESIGN: COMPARTILHAMENTO E DEMOCRATIZAÇÃO NAS PRÁTICAS DE PROJETO
}

\author{
OPEN DESIGN: SHARING AND DEMOCRATIZATION IN DESIGN PRACTICES
}

\author{
Camilo Simão de Lima ${ }^{1}$, Bruno Massara Rocha²
}

\section{RESUMO:}

O Open Design pode ser considerado uma concepção recente de trabalho decorrente de uma sociedade amplamente informatizada, cuja crescente tendência do compartilhamento de informação e de ações colaborativas vêm trazendo desafios e possibilidades para os processos criativos contemporâneos, principalmente no que se refere à produção e distribuição de serviços de projeto. O objetivo deste artigo é investigar os efeitos desta concepção de trabalho no campo de atuação de arquitetos e designers. Além disso, iremos analisar como a noção de abertura que a elas se encontram nomeadamente atreladas vêm se revelando na realidade projetual. Uma questão chave para conduzir esta investigação é: qual o real sentido e aplicação do conceito de abertura seja no desenvolvimento dos projetos, na interação entre os envolvidos ou na produção do conhecimento sobre o processo criativo como um todo? Este artigo realiza uma revisão bibliográfica detalhada sobre o tema Open Design em autores como (Anderson, 2012), (Bauwens, 2005), (De Masi, 2001), (Greenfield, 2017), (Lessig, 2005), (Schneider, 2017), (Stallman, 2015), (Von Hippel, 2005) e sugere quatro abordagens possíveis para a abertura: disciplinar, cognitiva, econômica e produtiva.

PALAVRAS-CHAVE: open design; democratização; compartilhamento; projeto

\section{ABSTRACT:}

Open Design can be considered a recent work conception resulting from a broadly computerized society, whose growing trend of collaborative actions and sharing information has brought new challenges and possibilities for contemporary creative processes, especially with regard to the production and distribution of design services. The aim of this article is to investigate the effects of this recent work conception in the design process of architects and designers. We will also analyze how is the namely notion of openness in the reality of projects. Key questions to conduct this investigation are: what is the real meaning and application of the concept of openness in the design process? How it affects the interaction between those involved? And how is helps the production of knowledge about the creative process as a whole? This article performs a detailed bibliographic review on the Open Design theme in authors such as (Anderson, 2012), (Bauwens, 2005), (De Masi, 2001), (Greenfield, 2017), (Lessig, 2005), (Schneider, 2017 ), (Stallman, 2015), (Von Hippel, 2005) and suggests four possible approaches to openness: disciplinary, cognitive, economic and productive

KEYWORDS: open design; democratization; sharing; design
Fonte de Financiamento:

Fundação de Amparo à

Pesquisa do Espírito Santo FAPES

Conflito de Interesse:

Declara não haver.

Submetido em: 172/02/2020

Aceito em: 08/07/2020

How to cite this article:

LIMA, C. S.; ROCHA, B. M. Open design: Compartilhamento e democratização nas práticas de projeto. Gestão \& Tecnologia de Projetos. São Carlos, v15, n3, p.6-17, 2020. https://doi.org/10.11606/gtp.v15i3.166815 


\section{CONTEXTUALIZAÇÃO}

Mudanças significativas no contexto produtivo e econômico da arquitetura e do design contemporâneos podem ser identificadas e relacionadas à difusão e capilaridade dos sistemas eletrônicos em múltiplos setores da atividade projetual. Em função das inovações trazidas pelos meios digitais, as concepções de trabalho, a oferta de serviços e os produtos desenvolvidos vêm se revelando substancialmente distintos do tradicional modelo industrial. Significa dizer que, de forma diferente a uma produção industrializada racionalizada centrada em bens materiais, consolida-se o setor terciário, marcado pela prestação de serviços customizados e pela produção de bens imateriais e informações. 0 setor terciário opera sob forte demanda de diversificação de produtos e serviços, exigindo novos posicionamentos quanto aos modos de se criar, pensar, representar, construir e comercializar a arquitetura e o design. Domenico De Masi (2001) define a conjunção dessas novas concepções de trabalho como parte de um corte epistemológico, isto é, uma nova potência organizacional e criativa cujo formato remete a um sistema aberto e flexível. Essa organização sistêmica define o que o autor considera ser uma ecologia organizacional composta por inúmeros posicionamentos, estratégias e abordagens, que abarca, dentre elas, o Open Design.

o Open Design é uma estratégia de trabalho que está intimamente relacionada aos processos criativos colaborativos e compartilhados impulsionados pelo digital e que tem como uma de suas características fundamentais a aproximação entre o produto e o usuário final, tendo em vista maior horizontalidade na oferta dos serviços de criação e produção do projeto. 0 termo Open Design é derivado da conjunção entre a palavra design (cuja conotação atende à definição do ato projetual), associado às práticas Open Source (Código Aberto - termo originalmente usado para identificar programas de computador cujos códigos podem ser utilizados, alterados e redistribuídos). A emergência do Open Design enquanto estratégia de trabalho tem relação direta com a democratização do acesso à informação proporcionada pelo surgimento da internet na década de 1990. Em paralelo com o progressivo ganho de fluidez e complexidade das redes eletrônicas, o surgimento e popularização dos equipamentos de fabricação digital foram determinantes para o amadurecimento do Open Design no contexto de arquitetos e designers.

Embora este cenário de abertura venha se consolidando como estratégia de trabalho nos últimos anos, resta saber se a democratização do acesso às informações vem acompanhada de uma democratização do acesso à prática projetual incluindo saberes, serviços e produtos. Muito tem sido questionado se os recursos tecnológicos atuais oferecem um repertório de aplicações criativas e inovadoras que permitam superar processos tradicionalmente fechados e centralizados pelo controle do projetista-criador ou pelas regras do mercado. É preciso avaliar se novas condições que têm sido criadas para se compartilhar informações por meio dos sistemas digitais interativos geram sociedades mais integradas, acessíveis e democráticas em termos de produção e troca de conhecimentos e acesso a bens e serviços de arquiterura e design. Nesse sentido, cabe analisar o alcance da abertura promulgada pelas estratégias Open Design e definir em que contexto e condições elas se instalam.

Este artigo tem como objetivo oferecer uma delimitação conceitual para o Open Design e identificar abordagens que nos permitam entender suas potencialidades e limitações no contexto projetual. Acima de tudo, pretende-se com este trabalho contribuir para ampliar o debate sobre o Open Design, sugerindo uma sistematização do conceito de abertura a partir de quatro recortes, a saber: cognitivo, disciplinar, econômico e produtivo.

Os procedimentos metodológicos se basearam em uma pesquisa bibliográfica de caráter qualitativo orientada em explorar, descrever e explicar o Open Design, demonstrando sua evolução por meio de uma breve genealogia e confrontando os olhares de autores 
referenciais como John Thackara (2011), Richard Stallman (2015), Lawrence Lessig (2005), Michael Bauwens (2005), Chris Anderson (2012), Nigel Cross (2011), Adam Greenfield (2017), dentre outros.

\section{BREVE GENEALOGIA DA ABERTURA: DO OPEN SOURCE AO OPEN DESIGN}

Um dos caminhos iniciais para compreender o conceito de abertura no universo digital é a análise do sistema operacional GNU Unix idealizado nos anos 80 por Stallman (2015). Esse projeto surgiu como uma alternativa para o mercado de softwares privados e a proprietização dos códigos-fonte, desdobrando-se posteriormente na General Public License (Licença Pública Geral). Em continuidade a esse projeto, o engenheiro de software Linus Torvalds desenvolveu em 1991 a plataforma Linux, sistema que popularizou a abertura dos códigos e ampliou significativamente o número de usuários dedicados ao desenvolvimento compartilhado de um sistema operacional gratuito. 0 código aberto (opensource) pode ser fundamentalmente definido como:

uma abordagem para o desenvolvimento de software e propriedade intelectual em que o código do programa está disponível para todos os participantes e pode ser modificado por qualquer um deles. Essas modificações são então distribuídas de volta à comunidade de desenvolvedores que trabalham com o software. Nessa metodologia, o licenciamento serve principalmente para divulgar as identidades de todos os participantes, documentando o desenvolvimento do código e os originadores de mudanças, aprimoramentos e derivativos (Warger, 2002, p.18).

O código aberto vem ampliando seu alcance nos regimes de trabalho atuais e instalando-se de forma definitiva no cotidiano de toda uma comunidade de desenvolvedores e programadores de diferentes áreas. Historicamente, a ampliação excessiva do contingente de iniciativas ditas abertas por parte de diferentes setores, especialmente os corporativos, fez com que uma parte desta comunidade de desenvolvedores, liderada por Eric Raymond, cunhasse a proposta free software que enfatizava não apenas a abertura das práticas de programação mas, principalmente, a liberdade como princípio fundamental. A despeito da existência de ambas denominações, opensource e free software, Stallman (2015) entende que elas são referentes a um mesmo movimento tecnopolítico.

Com a evolução das práticas e discursos orientados pela noção de abertura no contexto das redes digitais, dois posicionamentos tecnopolíticos fundamentais se manifestaram: um deles de origem conceitual, como é o caso de Erik Raymond, e outro de base operacional que, nos termos de Lakhani \& Von Hippel (2003), emerge em função dos benefícios que a ajuda coletiva oferece para a consolidação de um projeto de exigente complexidade. Seja no campo da produção de conhecimentos ou na produção de sistemas, o conceito de abertura foi sendo incorporado pelos mais diferentes campos, dando origem a iniciativas como: Open Data, Open Science, Open Education e Open University. Diante da necessidade de consolidar os valores de abertura no cenário político-cultural, a organização sem fins lucrativos Open Knowledge Foundation, sediada no Reino Unido, definiu que:

\footnotetext{
o conhecimento aberto se refere a qualquer conteúdo, informação ou dado que as pessoas estejam livre para usar, re-utilizar e redistribuir sem nenhuma restrição legal, tecnológica ou social (OPEN..., 2015).
}

Avital (2011) considera que o conceito de abertura evoluiu com o tempo e se cristalizou em três arquétipos: a) Inovação Aberta (Open Innovation), b) Código Aberto (Open Source) e c) Design Aberto (Open Design). 0 primeiro arquétipo, da inovação aberta, se articula à criação e disponibilizaçaão de iniciativas e projetos; o segundo está orientado para sua modelagem 
imaterial por meio de dados e informações; e o terceiro para sua materialização via processos de fabricação digital. Há um horizonte para que a abertura nos processos de fabricação digital da arquitetura possam se desdobrar em algo configurável, extensível e que possa ser gerado a partir de modelos comerciais distribuíveis e escalonáveis, fora das prateleiras, em meios de produção multiuso (Avital , 2011).

Grosso modo, o Open Design pode ser visto como a vertente da abertura dos códigos de informação no contexto de projeto de arquitetura, design, artes e práticas afins. 0 conceito apareceu pela primeira vez na literatura acadêmica no final do século XX, momento em que a Open Design Foundation se posicionou politicamente e formalmente favorável aos projetos cujos criadores permitissem a distribuição e documentação gratuitas, bem como modificações e derivações. A pesquisadora Heloisa Neves (2014), membro do grupo de discussão Open Design Definition da plataforma GitHub, afirma que para uma abertura plena, o projeto deve disponibilizar sua documentação completa via atribuição de licenças para modificar, distribuir, fabricar, prototipar e comercializar. Há uma clara aproximação com os princípios do código aberto, incluindo-se a produção material que, por si só, responde por uma nova e complexa etapa no projeto. Apesar disso, são ínumeras as questões que devem ser averiguadas e distinguidas dentro da complexa rede de possibilidades de reflexão e ação presentes no Open Design. Ao nosso ver, é essencial considerar uma abordagem que leva em conta os efeitos do compartilhamento de informações nas relações de trabalho e na produção democrática de conhecimentos, tendo como recorte principal o contexto dos bens e serviços de arquitetura e design.

\section{O COMPARTILHAMENTO E SEUS ELOS COM O CONHECIMENTO E A DEMOCRACIA}

A possibilidade da livre circulação de conteúdos e informações em redes digitais associada ao modo coletivizado como nos comportamos seguem trazendo alterações profundas na maneira como administramos nossas ações e nosso tempo dedicados ao trabalho, ao lazer e à interação social. 0 que se percebe é uma sobreposição crescente das atividades cotidianas em temporalidades híbridas sustentadas por suportes e plataformas digitais. As relações de trabalho vêm se tornando progressivamente mais flexíveis (CASTELLS, 1999) e mais articuladas em comportamentos abertos que se refletem em processos sob demanda (just in time, just in place), fragmentação das jornadas, terceirização de serviços e, em especial, a livre apropriação de dados. Nesse contexto de livre circulação e troca de informações, o modelo peer-to-peer (BAUWENS, 2005) teve papel determinante para definir a dinâmica das relações na Web 2.0 e fomentar o surgimento do arcabouço teórico que busca organizar este regime livre de circulação de conteúdos e bens comuns. A ascensão dos bens comuns compartilhados criou as bases para uma nova economia (DE MASI, 2011), distinta das práticas tradicionais de mercado baseada em produtos industrializados e mais em acordo com a flexibilização dos processos na sociedade digital interconectada e hibridizada (HIPPEL, 2005).

Benkler (2006) acredita que a emergência de uma nova economia baseada na livre comunicação telemática reflete o relativo ganho de autonomia por parte da sociedade e seu desejo, pelo menos em parte dela, por um maior envolvimento com os processos que dão origem aos produtos que elas necessitam. Elas têm em mãos os instrumentos necessários para buscar e computar dados, alterar conteúdos, aprender e distribuir conhecimentos sobre os processos que, segundo o autor, fazem com que o regime do capital ganhe uma nova camada de valor: a cognitiva. Fato é que não é a primeira vez que há um envolvimento da sociedade com o compartilhamento de conteúdo e conhecimento, embora estejamos numa 
fase de sua aceleração ao ponto de redefinir valores, oportunidades, plataformas e modos de interação com incontestáveis efeitos econômicos.

São inúmeras as alterações que o compartilhamento digital de conteúdos traz para os domínios do conhecimento e das relações econômicas. John Thackara (2011) enxerga de forma positiva estas mudanças e menciona o enorme potencial que o sistema peer-to-peer tem para a regeneração das economias locais. Ao mesmo tempo faz ressalvas quanto ao tipo de dados e informações que expõem usuários, e ao mercado de fake news. Dentre as contribuições, o autor destaca: a importante capacidade de integração sistêmica entre pessoas, lugares, informações; o investimento em atividades criativas e de maior valor agregado em polos de inovação; o fortalecimento dos elos entre pessoas e empresas como forma de resiliência e integração em tempos de crise. Para Lessig (2005) a internet tem papel determinante na constituição da cultura contemporânea. Se por um lado ela permitiu a criação e a produção de informações em massa, por outro ela também deu origem a um mercado de dados digitais que nos mapeiam e impõem novos problemas no modo como decidimos construir e gerir nossa própria cultura. Com o crescimento destas práticas de captura de dados, que trabalham no sentido de favorecer grandes corporações, gigantes de mídia, instituições privadas, Lessig (2005) reforça a necessidade de lutar pelo crescimento e evolução de um sistema de relações e trocas mais livres, mais abertos e baratos, que favoreça a democratização do acesso. 0 autor conclui afirmando que o desafio central do século XXI é configurá-lo um século de trocas, com repertórios legais e instrumentais que deixem claro o funcionamento dos recursos e instrumentos existentes para que usuários se sintam à vontade para escolher a maneira como querem criar, produzir e comercializar.

O movimento software livre reconhece que o compartilhamento de descobertas e soluções fortalecem uma corrente de inovações destinadas ao bem comum e que a contribuição de agora retornará no futuro sob a forma de um novo e melhorado sistema. Acima de tudo, notase uma associação entre o compartilhamento e a produção de conhecimento, um movimento contínuo de trocas entre o fazer e o aprendizado. Os resultados são de uma ordem de atribuição de valor que não se encontram no produto em si, mas na inteligência dos serviços que ele permite conduzir e na produção do conhecimento que ele gera.

Segundo Malini (2009), o conhecimento é o bem primordial no regime contemporâneo das trocas digitais. A partir da circulação de saberes e da socialização do conhecimento vemos emergir um novo regime de valores e trocas ao qual o autor denomina capitalismo cognitivo. O capitalismo cognitivo está estruturado por uma rede de informações compartilhadas cuja assimilação por parte de toda a comunidade de usuários produz uma inteligência coletiva descentralizada que avalia a contribuição de cada dado compartilhado e sua aplicabilidade nos projetos em desenvolvimento. Quanto maior e mais relevante for o impacto das informações compartilhadas, maior será sua reprodutibilidade e consequentemente seu reconhecimento por parte da comunidade de usuários. 0 que chama atenção neste processo são as motivações existentes por trás de uma economia de trocas que não se desdobra diretamente em lucro financeiro. Uma forma de entender tais motivações é considerar as reflexões de Bowens (2005) quando argumenta que o modo de produção em pares (P2P) de fato não se estrutura em um modelo de mercado tradicional baseado no lucro financeiro tampouco em uma produção pública desenvolvida pelo Estado. Segundo o autor, trata-se de um tipo de produção orientada pelo valor de uso (conhecimento) e não de troca (capital). Parte do princípio da cooperação entre a comunidade envolvida que administra de forma autônoma o conteúdo disponibilizado cabendo a ela avaliar e qualificar as contribuições. Bauwens (2005) define a horizontalidade do processo de disponibilização das informações como holoptismo, em contraponto ao conceito de panoptismo elaborado por Foucault, cujo significado faz referência à centralidade do poder e ao controle de suas ramificações. Nesta concepção do "olho que tudo vê" uma pequena parcela do sistema tem poder de vigilância e decisão sobre todas as outras derivações. Por outro lado, na concepção holóptica, todos os 
envolvidos do sistema têm possibilidade de visualizar e acompanhar as ações e reflexões dos demais e programar sua atuação sobre e a partir do que é produzido em comum. Se não há uma remuneração diretamente envolvida nas trocas realizadas, o sentido da prática tem motivações de ordem principalmente cognitiva bem como tecnopolítica, alimentada em grande medida pelo desconforto com a postura panóptica imposta aos regimes de propriedades. A concepção holóptica, baseada no modelo voluntário cooperativo, adota a postura afim aos bens comuns compartilhados, sugerindo novos modos de exercício democrático.

0 tema dos processos cooperativos e compartilhados exige atenção naquilo que diz respeito aos direitos de propriedade intelectual privada representados pelo copyright. Lessig (2005) afirma haver um desequilíbrio entre a forma como o copyright é aplicado e o modelo compartilhado de trabalho sugestivamente denominado copyleft. A rigidez nos pedidos de permissão para utilização, reprodução e divulgação do copyright são incompatíveis com a tendência que se forma no âmbito das práticas projetuais de acessar, baixar, editar e reproduzir conteúdos, enrijecendo o campo de novas oportunidades criativas e inventivas baseadas no bem comum.

Para Negri (2005), sugerir propriedades comuns é uma forma de resistência biopolítica ao que alerta ser uma forma de sequestro criativo por parte capital e de produções exclusivamente privadas que nascem no âmbito de uma sociedade baseada nas trocas. 0 conceito de bens comuns, associado à liberdade sobre o direito de propriedade, é central para sustentar movimentos e discursos que, de modos particulares, se posicionam contra a hegemonia financeiro-liberal global. Ele encontra nos fundamentos do Open Design uma de suas manifestações mais relevantes no início do século XX.

Filho \& Cruz (2019) sintetizam o comum como um conjunto de prática geridas pelo compartilhamento e reciprocidade de bens, espaços e produtos, para além do âmbito do Estado e do mercado e das formas de propriedade públicas e privadas. Dentre muitas acepções do termo, o Open Design epistemologicamente se encontra no que os autores definem como comum artificial, ou seja, um conjunto de produções cognitivas, trabalhos intelectuais, em grande parte resultantes da interação social e cultural. Apoiados na visão de Michael Hardt e Antonio Negri, os autores destacam os posicionamentos políticos que se encontram associados a estas produções: o comum como um princípio de ação contra a nova razão neoliberal que não se restringe a um regime econômico mas um modelo de competição de mercado engendrado em todas as esferas da nossa vida.

Apesar do discurso do comum já estar em circulação em diferentes áreas do conhecimento, no contexto do Open Design ainda existem muitas limitações para sua efetiva consolidação que são apontadas por Atkinson (2011) e De Mul (2011). Dentre elas, a abertura dos direitos de propriedade de inúmeras produções existentes necessárias para a evolução do conhecimento projetual como é o caso dos softwares CAD/CAM. Além disso, há necessidade de alteração do paradigma idealizado do arquiteto como profissional de criação engenhoso, mas solitário, imerso em suas elucubrações privadas, a ponto de desassociar sua produção de diversos eventos da realidade do mundo incluindo os usuários, o lugar e os recursos financeiros.

Em termos práticos, a gestão democrática do Open Design foi objeto de trabalho e estudo de Lessig na Stanford University, resultando na criação da organização sem fins lucrativos denominada Creative Commons (CC). Seu objetivo foi elaborar diferentes tipos de licenças de utilização do trabalho material e intelectual dos criadores ao redor do mundo de modo a agenciar com clareza qual tipo de concessão, direitos e deveres dos usuários estão atrelados a cada uma destas produções. A mais ampla de todas é a licença de atribuição, que permite distribuir, exibir, copiar e realizar trabalhos derivativos de uma determinada obra, desde que 
a autoria original esteja sempre junto a ela ou a suas derivações. Há ainda licenças nãocomerciais, licenças de compartilhamento de obras derivadas sob a mesma condição e licenças sem derivação, que permitem apenas a exibição, reprodução e distribuição. Tais licenças visam a identificação das produções de modo seguro e variável, deixando a cargo do criador a atribuição do modo de compartilhamento mais adequado à sua obra. Para Lessig (2005) a atribuição de licenças Creative Commons é uma garantia de liberdade democrática e politicamente expressa um ideal de superação da dicotomia proprietária "todos" versus "nenhum". A importância política do Creative Commons é evitar que o próprio sistema de propriedade capture as produções abertas redirecionando-as novamente ao campo mercantil. Malini (2007) adverte que, sem uma proteção como a que se propõe realizar a CC, os princípios do comum caminhariam para a tragédia e correriam o risco de ter seu excedente mantido sob a tutela do capital. A regulação jurídica tem efeito complementar à produção em pares e garante liberdade e segurança para a publicização das produções, fortalecendo o processo democrático e combatendo possíveis tentativas de atuação do capital sobre a construção coletiva. Podemos reconhecer claramente uma intenção política na garantia da liberdade do movimento copyleft que não se coloca em posição de competição com o copyright, mas de uma complementação tática necessária para criar condições para a evolução de uma cultura livre e aberta.

\section{A ABORDAGEM DO OPEN DESIGN SEGUNDO QUATRO NÍVEIS DE ABERTURA}

No momento em que se faz visível a complexidade de alterações nas relações humanas advindas do compartilhamento ampliado de conteúdos, surge uma demanda por um entendimento mais contextualizado dos seus efeitos no campo da arquitetura e do design. Os desdobramentos tecnopolíticos, comportamentais, legais e operacionais da abertura de dados vêm exercendo papel decisivo na produção de conhecimento sobre projeto e desenvolvimento de produtos. Nesta seção trazemos uma interpretação qualitativa e sistematizada do processo de abertura que toca em quatro níveis específicos de ação do Open Design: disciplinar, cognitivo, econômico e produtivo. 0 objetivo é propor apontamentos estruturados que fazem distinção a determinados níveis de ação identificados na revisão bibliográfica. Os quatro níveis de ação são resultantes desta interpretação e se colocam como abordagens distintas e autônomas dedicadas a um tema específico.

\section{ABERTURA DISCIPLINAR}

A abertura disciplinar tem relação direta com a produção de conhecimento de projeto. Seu teor transgressivo e tecnopolítico em defesa da liberdade de apropriação de informações deu origem ao Open Design Manifesto publicado em 2011, que considerava a abertura:

uma escolha, não uma predefinição. Caso fosse uma predefinição, não haveria necessidade de instruções, ideológicas ou não. Esforços ideológicos necessitam regras, códigos de conduta, manuais, por vezes excessivamente dogmáticos (KADUSHIN, 2010).

Alimentada por um forte ímpeto de experimentação e criação de ideias, a abertura disciplinar pode ser entendida como a que reconhe e incentiva posturas projetuais de natureza livre, intuitiva, pública e por que não amadora. Neste caso, a postura amadora não é sinônimo de falta de qualidade, mas o ímpeto para se buscar meios necessários para se obter um resultado prático. As fronteiras entre o formal e o informal se borram na abertura disciplinar. Isso significa que ela contempla procedimentos de origem não acadêmica e profissional, ou produções resultantes de inúmeras formas e fontes "não autorizadas" de exercício criativo. 0 conhecimento mutualizado, sobre o qual se apoia a visão de Giddens (1996), auxilia no 
entendimento desta informalidade, como uma espécie de conhecimento de base, configurativo, resultado do enfrentamento dialógico de fatos em aberto e em constante processo de experimentação e atualização.

0 que se entende como mutualização do informal é o processo de combinação de repertórios disponíveis, ou o que Bourriaud (2009) define como uma prática do híbrido. 0 exercício democrático da abertura disciplinar está atrelado à própria liberdade para errar. Num processo de projeto o erro é necessário, principalmente nas etapas mais fundamentais de desenvolvimento da ideia, momento em que se requer um conhecimento divergente (JONES, 1992), exploratório e apto a correr riscos. Reflexos desse conhecimento encontram-se no movimento maker e no agenciamento do do-it-yourself ou do-it-with-others. 0 movimento também opera no contexto amador, rústico, informal, fortemente atrelado às soluções originais e experimentais. Em um cenário de abertura disciplinar valemo-nos do pensamento de Anderson (2012) que afirma que a grande transformação que vem ocorrendo na sociedade não está na forma como as coisas estão sendo feitas, mas sim em que as estão fazendo.

Portanto, a abertura disciplinar reconhece que caminhos importantes para a produção do conhecimento não dependem de categorias acadêmicas necessariamente. Acima destas categorias encontra-se o inventor, o artífice, que ora se revela como programador, arquiteto, designer ou cientista.

\section{ABERTURA COGNITIVA}

A abertura cognitiva está diretamente relacionada com a disciplinar, embora ela se faça presente na forma como a liberdade de trânsito entre categorias formais e disciplinares produz uma nova forma de aprendizado calcado no coletivo. Se na abertura disciplinar qualquer um pode fazer, na cognitiva qualquer um pode aprender. A descompartimentação dos conhecimentos não elimina sua importância, mas redefine sua forma de criação por meio de redes digitais dinâmicas de troca. Essa abertura para o aprendizado via redes digitais coletivas já foi prevista por Lévy (1998) sob a terminologia ecologia cognitiva. Nos termos do autor, a formação dessa ecologia é fluida, dinâmica e distribuída, e define uma condição plural de difusão de saberes gerenciada por singularidades associadas. Nos processos projetuais atuais, muitas das respostas, referências, blocos, especificações, componentes necessários para o desenvolvimento de um projeto estão acessíveis digitalmente. Não é raro encontrar pessoas de formações diversas desenvolvendo trajetórias de aprendizado de projeto individualizadas e integralmente mediadas por redes digitais. As temáticas são variadas, e capazes de atingir um nível de competência surpreendentemente viável.

Um desdobramento visível é a proliferação de canais de aprendizado digital dedicados a um público interessado em projetos, desenvolvimento de produtos, autoconstrução, reformas, organização, cultivo de plantas, de forma totalmente autônoma. Esse tipo de aprendizado tem alcance limitado, mas atende plenamente problemas de menor complexidade, como é o caso da redução de custos que será abordada na abertura do nível econômico.

Os trabalhos realizados por Thomaz Lommée, Ronen Kadushin, Santiago Cirugeda e Jens Dyvik, embora tenham objetivos distintos, são exemplos importantes de serem mencionados em função da abertura dos projetos ao envolvimento cognitivo das pessoas. No projeto Open Structures este envolvimento é proposto por meio da disponibilização de informações legais, técnicas e administrativas sobre como construir ou desenvolver um projeto, incluindo especificações gerais, orientações, mecanismos de busca, bancos de dados de produtos, redes de contato, etc. Em um suporte digital de fácil acesso, Thomas Lommée disponibiliza um conjunto de componentes modulares, conectores, juntas e adaptadores que podem ser utilizados na restauração de móveis e equipamentos domésticos. Os componentes respeitam um sistema métrico unificado no formato de um grid de pontos e linhas de referência de 
modo a padronizar os encaixes e as combinações entre as peças. Lommée vislumbra uma condição de plena autonomia dos usuários em ter o controle sobre o processo criativo e construtivo. Sua proposta caminha em paralelo com a noção de autores como Rocha (2015), Cross (2011), Papanek (2009), de que o conhecimento projetual é intrínseco a qualquer ser humano, assim como a habilidade para criar, transformar, adaptar e improvisar.

\section{ABERTURA ECONÔMICA}

Conforme visto anteriormente, há um processo de flexibilização das relações de trabalho que está relacionada à abertura econômica instaurada pelos sistemas digitais e pelo compartilhamento de dados. Esta nova economia descrita pelos autores De Masi (2011), Benkler (2006) e Bauwens (2005) não é alheia ao fato de que ao comprarmos um objeto ou serviço estamos indiretamente pagando frações de valores distribuídos em toda sua cadeia produtiva que inclui logística, impostos, pagamento de funcionários, manutenção de maquinário, juros de bancos, taxas de administração etc. No contexto projetual essa rede produtiva tradicional também se aplica. Entretanto, novas iniciativa de disponibilização de pacotes de informação de projeto podem ser identificadas e consideradas reações de abertura a esta estrutura produtiva. Baseando-se na fabricação digital localizada, personalizada e mais barata, estas informações incluem modelos gratuitos de peças e encaixes, bibliotecas para programação, templates de modelos $3 \mathrm{~d}$, plataformas online de criação e configuração de objetos, roteiros de execução de projetos, blocos de equipamentos, tabelas de orçamentos, arquivos no formato STL para impressão 3d, etc. A abertura econômica está apoiada na possibilidade de apropriação de dados digitais licenciados sem a necessidade de pagamento de custos indiretos. No entanto, a abertura econômica traz a demanda por maior disponibilidade de tempo e dedicação por parte dos usuários para a produção do projeto. Grande parte destes dados encontram-se em repositórios digitais como Thingiverse, Instructables, GitHub cujas interfaces se estruturam como verdadeiras redes sociais de inventores de garagem. Hippel (2005) nos lembra que usuários e pequenos fabricantes tendem a construir seus protótipos com significativa economia modificando produtos disponíveis no mercado, adaptando-os a um novo propósito. Em termos econômicos, cabe ainda retomar a discussão anterior acerca do capitalismo cognitivo cuja forma de produção é essencialmente imaterial. A abertura econômica ocorre no momento em que a proliferação de formas de cooperação social produtiva gera uma forma de trabalho que independe dos meios de produção material e foca na produção do saber (Cocco et al, 2009). Isso significa uma migração do valor do produto em si para o valor das informações que podem nos levar a produzir autonomamente a solução que o produto busca resolver. Quanto maior a diversidade, a credibilidade e a rapidez de acesso a informações que um usuário pode oferecer, maior a relevância e, consequentemente, o valor do seu trabalho imaterial.

\section{ABERTURA PRODUTIVA}

Uma última interpretação das aberturas oferecidas pelo Open Design tem teor operativo e está diretamente ligada à revolução da robótica e dos mecanismos de fabricação digital. As máquinas de fabricação digital podem ser consideradas a espinha dorsal do Open Design e seu elemento de diferenciação produtiva frente às outras áreas da construção e da indústria. A abertura produtiva tem como principal manifestação física as fábricas robotizadas de pequeno porte e alta complexidade. Os recursos de fabricação digital tornaram realidade um conceito postulado pelo ciberneticista John von Newman em 1966: o do construtor universal. A máquina idealizada pelo matemático húngaro se manteve no universo das possibilidades até poucas décadas atrás. Ela foi concebida a partir da aplicação da teoria dos sistemas no contexto operacional do setor produtivo e teria a capacidade de extrair os recursos naturais, 
processá-los, organizá-los de acordo com uma necessidade específica e produzi-los autonomamente. Além disso, uma das características mais marcantes do construtor universal seria a capacidade de realizar inúmeras cópias de si mesmo. Greenfield (2018) explica que a máquina idealizada por Neumann inspirou inúmeros cientistas, dentre eles Adrian Bowyer, engenheiro e professor da Universidade de Leeds. Bowyer foi responsável por desenvolver a primeira máquina replicante (RepRap), de escala reduzida, baseada na técnica da impressão 3d e apta a imprimir grande parte de seus próprios componentes. A RepRap é um projeto de código aberto que acompanhou até os dias atuais a queda dos custos de produção, o aumento do interesse, o crescimento do conhecimento sobre os processos por impressão $3 \mathrm{~d}$ e atinge atualmente um status de elemento potencialmente transformador de todo o sistema econômico, produtivo e cultural (Greenfield, 2018). Ainda assim, muitos são os desafios a serem enfrentados pela abertura produtiva: como lidar com a escassez de recursos naturais para construção? Como associar robotização e mão-de-obra nos países em desenvolvimento? Como aproximar a produção das fontes de matéria-prima? Qual a morfologia e metodologia mais adequada a cada máquina?

Greenfield (2018) alerta que os atuais recursos de fabricação digital ainda estão restritos a nichos específicos, apresentam custo comparativamente alto e se concentram nos locais que menos precisam deles. Ademais, o processo de prototipagem gera uma quantidade considerável de lixo seja ele residual dos processos subtrativos, como o corte a laser ou CNC, ou derivados de suportes nos processos aditivos, como a impressão $3 \mathrm{~d}$.

As fábricas de pequeno porte têm papel fundamental para ampliar as possibilidades de crescimento do Open Design na prática projetual. Hippel (2005) explica que estes espaçosfábricas-laboratórios conectam redes de interesse comum e territorializam um processo mais amplo de democratização da inovação. No entanto, o acesso a uma realidade plenamente democrática passa pela redução expressiva dos preços dos insumos, equipamentos e ferramentas, pela força política em defender a manutenção das licenças Creative Commons para hardware e software, e pelo investimento em conhecimento processual e operacional localizado e contextualizado.

\section{ANÁLISES E DIRECIONAMENTOS FINAIS}

Após extensa verificação de fontes de referência, ratificamos o entendimento do Open Design enquanto uma concepção de trabalho extremamente complexa, fluida e configurada pela superposição de muitos atores e muitas técnicas. Sendo complexa, ela tende a se reconfigurar ao longo do tempo, e evoluir. Para o presente momento, os pontos principais que gostaríamos de destacar para direcionar futuras reflexões sobre o Open Design são: o seu significado dinâmico que dá margem para mal-entendidos e concepções pouco aprofundadas; a sua importância como instrumento de ação tecnopolítica; e as diferentes escalas de sua integração com os processos de projeto dentre os quais incluindo-se o urbanismo.

Em termos gerais foi verificado que o Open Design é uma concepção de trabalho ampla, mas que pode ser entendida como uma interação estratégica de indivíduos que, motivados pela herança do movimento código aberto, têm investido tempo e esforços no compartilhamento de informações, na personalização de produtos e serviços e na fabricação autônoma. No entanto, cabe alertar que o uso do termo Open Design pode se apresentar controverso em setores, por exemplo, de forte orientação comercial. Podem ser encontradas interpretações que o associam a uma espécie de metodologia empresarial, ou um ramo específico de negócios, e até mesmo como uma estratégia de branding. No entanto, considerando as origens do movimento tal qual foram apresentadas aqui e levando em conta seus principais conceitos de referência, nos parece claro que estas visões excessivamente mercantis 
distorcem o sentido do movimento. Temos clareza de que o Open Design não pode ser vinculado a uma única definição bem como não convém estar associado a uma metodologia específica. Além disso, autores como Lima \& Rocha (2018) e Lima (2018) nos mostram que o Open Design pode se fazer presente simplesmente em uma escolha, uma opção pessoal, que poderíamos considerar como tecnopolítica no sentido de que respeita determinados procedimentos democráticos no uso dos recursos sociotécnicos. Nos parece importante ressaltar que há muitas formas de se "abrir" um projeto e muitas estratégias para desenvolver conteúdos compartilhados. 0 que buscamos fazer neste artigo é pavimentar caminhos de interpretação que tornem mais claro aos arquitetos "o que está aberto", "por que isso é importante" e "como podemos aplicar em nossos projetos".

Mesmo compreendendo que a evolução do conceito de abertura sempre esteve de alguma maneira atrelada ao movimento Open Source, existem distinções importantes quando tratamos do Open Design no âmbito da arquitetura. A materialidade da arquitetura envolve, invariavelmente, custos na produção, na fabricação, na mão-de-obra e na manutenção, e esse é um aspecto importante em termos de complexidade na sua aplicação em projetos desta natureza. Edifícios são radicalmente diferentes dos softwares quando olhados sob a ótica de sua realidade tangível e isso incorre em uma distinção primal do tempo e forma como a abertura atua no campo arquitetural.

Há também muitas escalas de aplicação do Open Design. Ele pode transitar desde pequenos objetos de design, equipamentos de uso cotidiano, projetos de arquitetura ou mesmo propostas de urbanismo. Em cada uma delas existem inúmeras particularidades. Quando se compra um mobiliário hoje em dia em lojas especializadas, ele geralmente encontra-se desmontado e armazenado fora da cidade e chega até o local solicitado através de uma transportadora, para que seja então montado e instalado por mão-de-obra especializada ou pelo próprio comprador. Numa ótica de abertura do processo produtivo, seria mais desejável que as próprias pudessem ser auxiliadas a projetar seus próprios móveis e os produzissem em pequenas fábricas localizadas próximas às suas casas. Haveria assim uma redução potencial do custo de armazenamento, de transporte, além de um ganho de valor de uso em função da sua personalização.

Em termos urbanos, é de extrema importância que o poder público comece a repensar nossas cidades como entidades compartilhadas, pertencentes a todos, fomentando novas formas de experienciá-las e usá-las. É necessária a retomada da cidade como um bem comum que, mesmo estando globalmente conectada, seja localmente produtiva. 0 governo Catalão vem adotando desde 2016 esse tipo de abordagem por meio da iniciativa CatLabs (Laboratórios Catalães), uma tentativa de inserção dos cidadãos em uma rede de reflexão e ação urbana organizada como um modelo de cidade laboratório. Esse tentativa de criar um ecossistema urbano laboratorial é parte integrante de um processo de renovação democrática que entende a participação dos cidadãos como algo que deva ir além da participação em audiências públicas e eleição de representantes. Para o governo catalão, o poder de "co-criar e co-construir a cidade" é indispensável para a sua retomada enquanto lugar da democracia. Para que isso ocorra, há uma necessidade de transferência de parte da responsabilidade de decisão para os usuários-cidadãos, e isso demanda um amplo repertório de interfaces acessíveis, adaptadas à linguagem popular, fáceis de usar e de consultar. Schneider (2017) alerta que muitas plataformas ditas abertas ainda são desenvolvidas com enormes limitações de interface, tornando-as assíncronas em termos de troca de informações entre usuários e entidades envolvidas. Ainda há uma deficiência na maneira como as plataformas permitem a colaboração simultânea entre usuários, de forma a permitir que a troca de conhecimentos e ideias ocorra em tempo real. Isso faz com que, em muitas situações, seja limitada a participação dos usuários no desenvolvimento real do processo, manifestando-se um claro prejuízo para a fluidez do envolvimento compartilhado. É indispensável que se diminuam as barreiras instrumentais para potencializar dinâmicas de participação em projetos, permitir a 
criação de contextos sociais engajados, mesmo que seja mais custoso manter o controle de aptidões descentralizadas.

Para que haja uma evolução nos processos de compartilhamento no contexto da cidade, é necessário que haja um investimento maior desenvolvimento de estratégias de metadesign, produzindo ambientes digitais estruturados para a participação dialógica coletiva. Plataformas digitais bem projetadas podem promover arranjos coordenados de singularidades visando mobilizar competências e, consequentemente, descentralizar o conhecimento sobre a cidade.

É desejável o envolvimento de profissionais de design, artes e arquitetura com um profundo processo de autocrítica reconhecendo a realidade de um mundo conectado e articulado em rede. Estamos vivendo uma transformação na forma como as pessoas se relacionam, criam, produzem e negociam, e o Open Design parece trazer tanto contribuições quanto questionamentos que somente poderão ser assimilados a partir de participações efetivas dos arquitetos neste processo. Essa participação é essencial para que continuemos explorando e implementando interfaces técnicas coerentes com nossa sociedade em rede. Nesse caminho teremos chances de, como recomenda Anderson (2012), transformar democraticamente para melhor o mundo real com processos inéditos.

\section{Referências Bibliográficas}

ANDERSON, Chris. Makers: the new industrial revolution. NewYork: Crown Publishing Group, 2012.

ATKINSON, P. Orchestral Manoeuvres In Design. In: Open design now: Why Design Cannot Remain Exclusive. Amsterdam, The Netherlands: BIS publishers, 2011. p. 24-31.

AVITAL, Michel. The Generative Bedrock of Open Design. In: VAN ABEL, B. et al. Open design now: Why Design Cannot Remain Exclusive. Amsterdam: BIS publishers, 2011. p. 48-58.

BAUWENS, Michel. The Political Economy of Peer Production. 2005. Disponível em: https://www.informatik.uni-leipzig.de/ graebe/Texte/Bauwens-06.pdf. Acessado em: 15/02/2020.

BENKLER, Yochai. The wealth of networks: how social production transforms markets and freedom.

2006. Disponível em: http://www.benkler.org/Benkler Wealth Of Networks.pdf. Acessado em: 15/02/2020.

BOURRIAUD, N. Pós-produção: como a arte reprograma o mundo contemporâneo. São Paulo: Martins Fontes, 2009.

CASTELLS, M. A Sociedade em rede. São Paulo: Paz e Terra, 1999.

COCCO, Giuseppe; VILARIM, Gilvan. Trabalho imaterial e produção de software no capitalismo cognitivo. In: Liinc em Revista, v.5, n.2, setembro 2009, Rio de Janeiro, p. 173-190. DOI: https://doi.org/10.18617/liinc.v5i2.315.

CROSS, N. Design Thinking: understanding how designers think and work. London: Bloomsbury Academic, 2011.

DE MASI, Domenico. O futuro do trabalho: fadiga e ócio na sociedade pós-industrial. Rio de Janeiro, RJ: José Olympio, 2001. 
DE MUL, J. Redesigning Design. In: Open design now: Why Design Cannot Remain Exclusive. Amsterdam, The Netherlands: BIS publishers, 2011. p. 34-39.

FILHO, João B. M. T; CRUZ Mariana M. O comum urbano em debate: dos comuns na cidade à cidade como comum? In: Revista Brasileira de Estudos Urbanos e Regionais. V.21, N.3, 2019. DOI: https://doi.org/10.22296/2317-1529.2019v21n3p487.

GIDDENS, A. Novas regras do método sociológico: uma crítica positiva às sociologias interpretativas. 2a ed. Lisboa: Gradiva, 1996.

GREENFIELD, Adam. Radical Technologies: the design of everyday life. Brooklyn, NY: Verso, 2017.

HIPPEL, E. V. Democratizing Innovation. Cambridge: The MIT Press, 2005.

JONES, J. C. Design Methods. 2nd. ed. New York: John Wiley \& Sons, 1992.

KADUSHIN, Ronen. Open Design Manifesto. 2010. Disponível em: https://www.ronenkadushin.com/open-design-manifesto. Acessado em: 15/02/2020.

LAKHANI, Karin R.; VON HIPPEL, Eric. How open source software Works: "free" user-to-user assistance. In: Research policy, v. 32, n. 6, 2003, p. 923-943. DOI: https://doi.org/10.1016/S00487333(02)00095-1.

LESSIG, Lawrence. Cultura Livre: como a grande mídia usa a tecnologia e a lei para bloquear a cultura e controlar a criatividade. São Paulo: Trama, 2005.

LÉVY, Pierre. As Tecnologias da Inteligência: o futuro do pensamento na era da informática. Rio de Janeiro: Ed. 34, 1998.

LIMA, Camilo S. Open Design: compartilhamento e democratização nas práticas de projeto. Dissertação de Mestrado. Orient. Prof. Dr. Bruno Massara Rocha, Março 2018. Vitória: PPGAU/UFES, 2018.

MALINI, Fábio. O valor no capitalismo cognitivo e a cultura hacker. In: Liinc em Revista, v.5, n.2, setembro, 2009, Rio de Janeiro, p.191-205. DOI: https://doi.org/10.18617/liinc.v5i2.311.

MALINI, Fábio. O comunismo das redes: sistema midiático p2p, colaboração em rede e novas políticas de comunicação na internet. Tese de Doutorado. Rio de Janeiro: UFRJ, 2007.

NEGRI, Antonio. A constituição do comum. Conferência Inaugural do II Seminário Internacional Capitalismo Cognitivo - Economia do Conhecimento e a Constituição do Comum. Rio de Janeiro, outubro, 2005.

NEVES, Heloisa. Maker innovation: do open design e fab labs...às estratégias inspiradas no movimento maker. Tese de Doutorado. São Paulo: FAUUSP, 2014.

OPEN KNOWLEDGE FOUNDATION. 2015. Disponível em: http://opendefinition.org.

PAPANEK, V. J. Design for the real world: Human ecology and social change. 2. ed. Chicago: Academy Chicago, 2009.

ROCHA, Bruno M. Complexidade e improvisação em arquitetura. Orientador: Carlos Roberto Zibel Costa. 2015. 256 f. Tese de Doutorado São Paulo: FAUUSP, 2015. 
Open design: Compartilhamento e democratização nas práticas

de projeto

ROCHA, Bruno M.; LIMA, Camilo S., Open Design: Principles, Interfaces and Values Analysis. XXII Congresso Internacional da Sociedade Iberoamericana de Gráfica Digital, Blucher Design Proceedings, Volume 5, 2018, Pages 1241-1249, ISSN 2318-6968. Disponível em: $<$ http://dx.doi.org/10.1016/sigradi2018-1451

SCHNEIDER, Christoph. Transforming TechKnowledgies: the case of open digital fabrication. Tese de Doutorado. Munique: Technische Universität München, 2017.

SENNETT, Richard. O Artífice. Rio de Janeiro: Ed. Record, 2012.

Camilo Simão de Lima camiloslima@gmail.com

Bruno Massara Rocha bmassara@gmail.com
STALLMAN, Richard. Free Software, Free Society: Selected Essays of Richard M. Stallman. Boston: Free Software Foundation, 2015.

THACKARA, John. Into The Open. In: VAN ABEL, B. et al. Open Design Now: Why Design Cannot Remain Exclusive. Amsterdam: BIS publishers, 2011. p. 42-45.

VON HIPPEL, Eric. Democratizing Innovation. Cambridge: The MIT Press, 2005.

WARGER, Thomas. The Open-Source Movement. Educause Quarterly, n. 3, 2002, p. 18-20. 